\title{
J. DERECHO PENAL
}

\section{RESUMEN}

\section{EL DELITO DE SECUESTRO}

\author{
Campo Elías Muñoz Arango \\ Universidad de Panamá \\ Facultad de Derecho y Ciencias Políticas \\ Departamento de Ciencias Penales y Criminológicas \\ E-mail: campoema@gmail.com
}

El secuestro es un delito grave que va en aumento, que atenta contra la libertad, en concreto la libertad ambulatoria por cuanto el sujeto no puede trasladarse de un lugar a otro, y en segundo lugar el patrimonio económico del mismo ya que está siendo obligado a entregar algo a cambio de su libertad. Al igual que en los delitos de privación de libertad, se afecta la libertad, sin embargo, en el secuestro consiste en secuestrar a la persona para obtener de ello o de otra como precio de liberación, dinero, bienes, información u otros documentos con efecto jurídico.

Palabras claves: secuestro, libertad, patrimonio económico, privación de libertad, lucro.

\begin{abstract}
ASBTRACT
Kidnapping is a serious crime that is increasing, which threatens freedom, in particular outpatient freedom as the subject cannot move from one place to another, and secondly the economic assets of the same as it is being forced to deliver something in exchange for your freedom. As in the crimes of deprivation of liberty, freedom is affected, however, in kidnapping it consists in kidnapping the person to obtain from it or from another one such as the liberation price, money, goods, information or other documents with effect legal.
\end{abstract}

Keywords: kidnapping, freedom, economic patrimony, deprivation of liberty, profit.

\section{Introducción}

En el Código Penal hay varios delitos que castigan hechos que atentan contra la libertad así tenemos, la Privación de libertad (art. 149),el Secuestro (art.150), la Extorsión y coacciones (art. 151), Desaparición forzada (art. 152), Detenciones ilegales (art.154-155),Someter al detenido a castigos o torturas inhumanas o degradantes (art.156), la Tortura (art. 156 A), la Retención o posesión ilegítima de pasaporte u otros documentos público de identificación (art. 157) y la Sustracción de menores e incapaces.

Se tutela la libertad de las personas frente actuaciones arbitrarias o ilegítimas que provengan de cualquier persona, incluyendo los servidores públicos, como son las detenciones ilegales, y también de aquellas actuaciones realizadas por particulares, como el secuestro y la extorsión.

En esta ocasión vamos a examinar el delito de secuestro frente al delito contra la libertad en nuestra legislación, también denominado por otros como delito de plagio o secuestro lucrativo (Guerra De 
Villalaz, 2016, p.82), que a partir del Código Penal del 2007 ha sido considerado como un delito contra la libertad, y no contra el patrimonio económico.

Al igual que ocurre en otros países, Panamá no ha podido escaparse de este hecho delictivo, realizado no solo por nacionales sino también por extranjeros, de manera que según datos del Observatorio de Seguridad Ciudadana del año 2017,se refleja que de los delitos denunciados, el $100 \%$ corresponde al secuestro (2017).

Asimismo, el Informe del año 2016, del Ministerio de Seguridad Pública (SIEC), manifiesta que en los secuestros por el significativo incremento del 61.78 de porcentaje de cambio en la tasa, durante el año 2016 se denunciaron 23, representando 9 casos comparado con el año 2015. Este fenómeno tan serio que el uso de las tecnologías ha hecho más vulnerable a las víctimas y termina facilitándole el trabajo a las redes criminales, mediante los denominados secuestros "express", modalidad cuyo objetivo es obtener dinero de una manera más rápida y expedita y no siempre los secuestradores piden elevadas cifras, a pesar de que algunos grupos delincuenciales son metódicos porque estudian y le dan seguimiento a sus víctimas antes de intentar secuestrarlas, existen secuestros que han surgido de forma fortuita en donde el delincuente sale y ubica a una persona, quizás por su ostentación y entonces se produce el hecho delictivo.

\section{Consideraciones previas sobre el delito de Secuestro y la privación de libertad}

El artículo 150 del Código Penal castiga el delito de secuestro, el cual ha sido reformado en varias ocasiones y la última reforma con la Ley 68 de 2009, que aumenta las penas para este delito y la fija para el tipo básico de quince a veinte años, y para el agravado se aumenta de un tercio hasta la mitad cuando se realice en cualquiera de los casos señalados en los numerales 1 al 8 de esta disposición.

La norma dice lo siguiente:

"Quien secuestre a una persona para obtener de ello o de otra como precio de liberación, dinero, bienes, información, documentos con efecto jurídicos por acción o por omisión o algún provecho a favor suyo o de un tercero, aunque no logre el fin perseguido, será sancionado con prisión de quince a veinte años.

Igual sanción se impondrá a quienes en reparto de funciones o tareas participen en la comisión del delito brindando aportes dirigidos a garantizar su consumación, aunque esta no se haya producido por la intervención de las autoridades competentes, y a quienes tengan conocimiento de la comisión del delito y omitan informar a las autoridades".

La pena señalada en este artículo se aumentará de un tercio a la mitad cuando el secuestro se ejecute:

1. En la persona que ostente inmunidad reconocida por el Derecho Internacional.

2. En un huésped o invitado del gobierno nacional o de cualquier ente público.

3. En un menor de edad con discapacidad, una mujer embarazada o una persona mayor de setenta años. 
4. En la persona de un pariente cercano o a aprovechando la confianza depositada en el autor o en alguno de los copartícipes.

5. Con el fin de obligar al gobierno nacional o a cualquier otro gobierno que realice o deje de realizar una acto.

6. En la persona de un miembro de la Fuerza Pública, del Órgano Judicial, del Ministerio Público, de la Autoridad Nacional de Aduanas y otros estamentos de seguridad pública o de parientes de dichos funcionarios, dentro del cuarto grado de consanguinidad y segundo de afinidad, y que el hecho sea motivo del resultado del ejercicio de sus cargos.

7. Por un miembro de un grupo insurgente o del crimen organizado, o por persona que haya ingresado al país para ejecutar el hecho.

8. Por una persona que ha sido o es miembro de uno de los organismos de seguridad del Estado".

Este delito en Panamá GUERRA DE VILLALAZ (2010, P.83) lo denomina como Plagio o Secuestro Lucrativo, para otros solo es Secuestro, y otros lo distinguen como secuestro extorsivo, que además de arrebatar, sustraer, retener u ocultar a la persona se le exige por su libertad algún provecho o cualquier utilidad (González Ferrer, 1977, p.171).

También tenemos que en algunos países se considera como delito contra el patrimonio, como lo tenía antes nuestra legislación de 1982, y otros dicen que solo es una privación de libertad agravada.

En Panamá, si vemos el Código Penal del 2007, el delito de secuestro no es igual al delito de privación de libertad, esto se desprende del concepto que establece el artículo 148, que castiga a quien "ilegalmente prive a otro de su libertad", del secuestro, que la norma dice que se "secuestra a una persona para obtener de ella o de otra, como precio de liberación, dinero, bienes, información, documentos con efectos jurídicos".

El artículo 149 castiga el delito de privación de libertad de la siguiente manera:

"Quien ilegalmente prive a otro de su libertad será sancionado con prisión de uno a tres años o su equivalente en días multa o arresto de fines de semana.

Si la privación de libertad fue ordenada o ejecutada por un servidor público con abuso de sus funciones, la sanción será de dos a cuatro años de prisión”.

Así dice FORTUNY BERENGUER (2015) el delito de secuestro se diferencia del de detención ilegal, en que en aquél existe el requisito de la condición, elemento que no concurre en la detención ilegal. Generalmente la condición como elemento del delito del secuestro es de carácter económico, pero puede tener otros contenidos

También desde el punto de vista gramatical secuestrar es Retener indebidamente a una persona para exigir dinero por su rescate, o para otros fines, por lo que en algunas legislaciones se contempla el delito de secuestro simple y el delito de secuestro extorsivo, que en este caso consiste en exigirle a una persona dinero por la retención, mientras que en el caso de la privación de libertad implica solo el encierro de la persona.

\section{Bien Jurídico Protegido}


El bien jurídico protegido es la libertad ambulatoria del sujeto porque estando encerrado o bajo cautiverio no puede trasladarse de un lugar a otro, y en segundo lugar el patrimonio económico del mismo ya que está siendo obligado a entregar algo a cambio de su libertad.

GONZÁLEZ FERRER (1977:174), explica refiriéndose al Código Penal de 1922 derogado que en ese momento tutelaba el patrimonio de manera directa, que el bien jurídico en su opinión consistía en la privación de la libertad del sujeto retenido, que no tiene movilidad, su libertad de movimiento resulta vulnerada por la acción de secuestrar a una persona para exigir a cambio precio por su liberación

Lo anterior constituye una de las novedades que presenta el Código Penal del 2007, pues el secuestro tradicionalmente considerado en nuestro país como un delito contra el patrimonio, se configura ahora, siguiendo el derecho comparado como un atentado contra la libertad. Con ello, se le asigna, a la libertad una tutela primordial que afecta la libertad ambulatoria o la libertad de locomoción, bien jurídico de significativa importancia en nuestra legislación que aparece tutelado después del derecho a la vida.

De conformidad con las Naciones Unidas, "el secuestro es un delito grave con consecuencias potencialmente dolorosas para las víctimas y sus familias, para las comunidades, los países y, por extensión, para la comunidad internacional. Hay pruebas convincentes de que muchas personas que sobreviven al secuestro nunca se recuperan totalmente del trauma que ocasiona. Los efectos sobre las familias de las víctimas, los amigos íntimos, los familiares y los colegas también pueden ser importantes. Cuando el secuestro es generalizado se plantean temores y dudas en la comunidad; esta falta de confianza puede contribuir a la incertidumbre social y política y a la declinación económica".

\section{Análisis del delito de secuestro}

1. El tipo de injusto: Tipo objetivo y subjetivo.

Sujeto activo es la persona que secuestra a otro. Puesto que cualquiera puede realizar este delito es un delito común, en la que generalmente hay varios sujetos involucrados.

Según las Naciones Unidas (2006), "muchos secuestros están muy bien planificados. Los secuestradores habrán considerado cuidadosamente dónde apoderarse de la víctima, qué armas y medios de transporte se necesitan, dónde se esconderá a la víctima y qué rutas de escape se utilizarán. De igual manera, es muy probable que hayan hecho un análisis de la víctima escogida, y de su familia o negocio, así como de su vida social y privada y sus lugares predilectos, y sus rutas y hábitos"

La persona secuestrada es el sujeto pasivo, que ve afectada su libertad, que puede ser cualquier persona, incluyendo las que aparecen contenidas en los numerales 1 al 8 del artículo 150 como son:

1. En la persona que ostente inmunidad reconocida por el Derecho Internacional.

2. En un huésped o invitado del gobierno nacional o de cualquier ente público.

3. En un menor de edad con discapacidad, una mujer embarazada o una persona mayor de setenta años. 
4. En la persona de un pariente cercano o a aprovechando la confianza depositada en el autor o en alguno de los copartícipes.

5. Con el fin de obligar al gobierno nacional o a cualquier otro gobierno que realice o deje de realizar una acto.

6. En la persona de un miembro de la Fuerza Pública, del Órgano Judicial, del Ministerio Público, de la Autoridad Nacional de Aduanas y otros estamentos de seguridad pública o de parientes de dichos funcionarios, dentro del cuarto grado de consanguinidad y segundo de afinidad, y que el hecho sea motivo del resultado del ejercicio de sus cargos.

7. Por un miembro de un grupo insurgente o del crimen organizado, o por persona que haya ingresado al país para ejecutar el hecho.

8. Por una persona que ha sido o es miembro de uno de los organismos de seguridad del Estado".

FEBRES CORDERO (1993:511) explica que hay una duplicidad de bienes jurídicos afectados, la libertad del secuestrado y el patrimonio del afectado, podemos estar en ocasiones ante un doble sujeto pasivo o simplemente un delito con un solo sujeto pasivo cuando coincide en la misma persona el ataque a la libertad y el daño al patrimonio.

La conducta castigada consiste en "secuestrar, que es privar de manera ilegítima de su libertad a otra persona para obtener de ella o de otra, como precio de liberación, dinero, bienes, información, documentos con efectos jurídicos. De esta manera, nos dice SERRANO GÓMEZ (2016; 103) que la persona se le encierra o detiene exigiendo una condición para su liberación, para poner fin a su secuestro, condición que se le puede exigir al secuestrado o a otra persona

Los medios de comisión del delito puede ser cualquier medio idóneo, como suele ser el fraude, engaño, amenaza, coacción, etc. o intimidación de dañar o matar a la persona secuestrada (Mendoza Tronconis, 1975, p. 214; Febres, 1993, p. 151), y el fin es obtener un provecho económico, ventaja, entre otros.

Se trata de delito permanente, de peligro y de daño, y no hay ningún inconveniente para que el mismo sea un delito de acción (Bramont Arias, 1997: 2187).

También la conducta en el segundo párrafo del artículo 150, establece el castigo para distintos comportamientos como son el brindar aportes o ayudas al secuestrador para que logre su cometido, que no es más que una participación criminal, elevadas a categoría de autoría. De igual forma, a los que omiten informar a las autoridades cuando se tenga conocimiento de un secuestro (conducta omisiva), en la que puede conjugarse acciones de un particular o un servidor público (art.83 C.P.P.), por ejemplo el de un médico que es llamado para atender y luego se entera de que la persona ha sido secuestrada.

Hay muchos tipos de secuestro según advierte las Naciones Unidas (2006), sin embargo, para efectos de este delito debe tener fines de provecho económico:

a) Secuestros "expreso", en que la víctima es secuestrada durante un período corto pero suficiente para obtener alguna concesión o ganancia financiera; 
b) De igual forma, hay otro tipo de secuestro en la que los secuestradores entran a centros comerciales buscando a menores de edad y les quitan los celulares, y luego llama a los familiares pidiendo el rescate,

c) El "secuestro virtual", en que inicialmente no hay ningún secuestro pero se exige un pago con el pretexto de que una persona (a menudo un pariente) ha sido secuestrado y se paga un rescate; una variante consiste en que, en el momento del pago, la persona que lo efectúa es secuestrada para asegurar un segundo rescate;

d) Secuestro con fines de extorsión, para exigir una suma de dinero, influir en decisiones empresariales u obtener una ventaja comercial;

e) Secuestro con fines políticos o ideológicos, cuyo objetivo puede ser destacar una reivindicación particular, crear una atmósfera de inseguridad (o reforzarla), obtener publicidad o influir en decisiones de gobiernos u otras entidades;

f) Secuestro entre grupos delictivos, o dentro de ellos, con el fin de cobrar deudas u obtener ventajas en un mercado delictivo particular o con fines de intimidación;

g) Secuestro vinculado a disputas familiares o domésticas, que en algunas jurisdicciones se conoce como "rapto";

h) Secuestro con fines de explotación sexual, que puede incluir el contrabando posterior de las mujeres y los niños a través de las fronteras nacionales;

i) Secuestro en el curso de otras actividades delictivas, normalmente para facilitar la adquisición de determinados productos, generalmente en el curso de un robo;

j) El secuestro simulado o fraudulento, en que la "víctima" actúa conjuntamente con otros o sola para obtener algún beneficio material o de otro tipo.

k) La venta de la víctima de un secuestro a otro grupo, igualmente motivado, que luego negocia el pago de un rescate

Por lo que respecta al objeto material recae sobre la persona secuestrada, es decir, cualquiera persona de manera indiferente, o sobre las personas enumeradas en los numerales 1 al 8 del artículo 150 del Código Penal. En el caso de nuestro país se han dado varios de esos tipos de secuestros según lo registran los medios de comunicación, como por ejemplo, la condena a una persona en abril de este año por haber fingido su propio secuestro en el año 2017 ( 6/2018)

GONZÁLEZ FERRER (1977:175), dice que el objeto material es la persona que resulta privada de su libertad de movimiento, la cual puede resultar además lesionada en su patrimonio.

En cuanto al tipo subjetivo, el secuestro es un delito doloso (directo), en la que el agente debe tener la intención de secuestrar, pero además de ello debe tener la finalidad de obtener como precio de liberación, dinero, bienes, información, documentos u otras cosas con efecto jurídico. En consecuencia, el elemento subjetivo es el provecho económico de la figura del secuestro lucrativo.

Hay una diferencia entre este delito y la privación ilegal de libertad (art.149), ya que en el primero la privación puede consistir en el encierro simplemente, en el secuestro por el contrario la privación arbitraria se realiza con el ánimo de obtener dinero, bienes, información, documentos con efecto jurídico, como precio de liberación.

\section{Formas de Aparición del Delito}


La consumación se produce desde el momento en que se secuestra al sujeto pasivo, se le encierra o detiene y se exige algo a cambio para ser liberada (Serrano Gómez, 2016:103), y no se requiere para la consumación que la persona no haya recibido el rescate u obtenido lo solicitado (Mendoza, 1975; 219), de manera que se consuma tan pronto se priva de libertad al sujeto.

El delito de secuestro es un delito permanente, la acción de secuestrar se prolonga en el tiempo mientras dure la privación de libertad, y es a la vez un delito de lesión (Bramont Arias, 1993: 189).

La tentativa es posible. BRAMONT ARIAS (1975:188) nos dice que en la práctica resulta difícil determinar los actos de inicio de ejecución del delito, y se cita como ejemplo de tentativa, cuando Jacinto y Federico, quienes quieren secuestrar a Heriberto, no logran su objetivo al lograr es deshacerse de ellos cuando lo iban a subir al carro.

En cuanto a la autoría y participación criminal, el Autor es el que realiza la acción descrita en el tipo, es decir, el secuestrador, propiamente tal, y a su vez el que omite denunciar cuando tiene conocimiento de ello, pudiendo intervenir otros personajes, como los guardadores de la víctima, los negociadores o los simples mensajeros. Ahora bien, en lo que respecta a esto último hay que señalar, que se trata propiamente de supuestos de participación criminal que en algunas legislaciones como la nuestra se elevan a categoría de autoría, conocida en la legislación derogada como favorecimiento de secuestro(art.189)que castigaba por ejemplo, al que llevaba correspondencia o mensaje escrito para obtener el secuestro.

La participación criminal solo es admisible en la forma de instigación, ya que la complicidad queda comprendida en el tipo, cuando habla del reparto de funciones o tareas de los que participan en la comisión del delito.

\section{Consecuencias Jurídicas}

La pena para quien secuestre a otra persona es de quince a veinte años de prisión. La misma sanción se aplicará a quienes participen en el hecho, y así como también a los que omitan denunciar el secuestro teniendo conocimiento de ello.

En el artículo 160 se establece que la pena podrá disminuirse a la mitad, si el autor pone espontáneamente en libertad a la víctima, antes de que se inicie investigación criminal, sin haber alcanzado el objeto que se propuso y sin causarle daño.

Por otra parte, en el tipo calificado de secuestro, previsto en el artículo 150, la agravación de la pena se fundamenta en atención a diversos criterios: a)con respecto a la persona que realiza el hecho, b)en relación al sujeto pasivo c) para obtener determinados fines ,aunque deba reconocerse que tales formulaciones no son las más aconsejables.

\section{Reflexiones finales sobre el secuestro como delito contra la libertad.}

El delito de secuestro y la privación ilegal de la libertad son delitos que afectan la libertad ambulatoria de las personas, y en el caso de este último aparece consagrada en el artículo 149 que dice lo siguiente: 
"Quien ilegalmente prive a otro de su libertad será sancionado con prisión de uno a tres años o su equivalente en días multa o arresto de fines de semana.

Si la privación de libertad fue ordenada o ejecutada por un servidor público con abuso de sus funciones, la sanción será de dos a cuatro años de prisión”.

En ambos delitos se tutela esa libertad ambulatorio o de movimiento que se ve afectada por estar encerrado o privado de su libertad, en otro caso privado de su libertad a cambio de obtener un provecho económico.

La Constitución de Panamá indica en su artículo 21 que nadie puede ser privado de su libertad, sino en virtud de mandamiento escrito de autoridad competente, expedido de acuerdo con las formalidades legales y por motivo previamente definido en la Ley, principio igualmente en convenios de derechos humanos. En los delitos contra la libertad como es el caso del secuestro cualquiera persona puede cometer este delito (salvo en los casos que la realiza un servidor público), son delitos comunes y monosubjetivo, y en muchas ocasiones más de una persona interviene en los mismos, como sucede en el secuestro. Sujeto pasivo es la persona privada ilegalmente de su libertad, en este caso secuestrada por el sujeto activo.

En cuanto a las conductas castigadas en la privación ilegal de la libertad, consiste en privar a otro, en el secuestro consiste en secuestrar, pero ambas tienen en común que la libertad de movimiento del sujeto queda afectada por ese encierro y privación, queda impedida de trasladarse o de ir de un lugar a otro.

De igual forma, hemos visto que el tiempo de duración de la privación de libertad no tiene importancia para que se dé el castigo por la privación o por el secuestro, pensemos por ejemplo, en el secuestro exprés.

Para terminar, en cuanto a las consecuencias jurídicas la privación ilegal de libertad se castiga con pena de uno a tres años de prisión o su equivalente en días multa o arresto de fines de semana, y con pena de dos a cuatro años cuando lo realice un servidor público. En tanto el secuestro se castiga más grave, con pena de quince a veinte años y agravada en los supuestos previstos en los numerales 1 al 8 del artículo 150 .

\section{BIBLIOGRAFÍA}

ACEVEDO, José Rigoberto, Derecho Penal, Parte General y Especial. Comentarios al Código Penal, Imprenta Taller Senda., Panamá, 2009.

ARANGO DURLING, Virginia, Derecho Penal, Parte General. Introducción y Teoría del delito, Ediciones Panamá Viejo, Panamá, 2013.

ARANGO DURLING, Virginia/ MUÑOZ POPE, Carlos, Delitos contra la Libertad, Facultad de Derecho y Ciencias Políticas, Universidad de Panamá, 1989.

CÁMARA DE COMERCIO, INDUSTRIAS Y AGRICULTURA DE PANAMÁ. Observatorio de Seguridad Ciudadana Programa de las Naciones Unidas para el Desarrollo Diagramación e Impresión / 
Editora Sibauste, S.A. Octavo Informe del Observatorio de Seguridad Ciudadana-Cuarta Edición / Febrero 2017@ Programa de las Naciones Unidas para el Desarrollo (PNUD)

BANACLOCHE PALAO, Julio, La libertad personal y sus limitaciones, detenciones y retenciones en el Derecho español, McGraw Hill, Madrid, 1996.

BENÍTEZ MORENO, Luis, Libertad protegida, Introducción al estudio de los delitos contra la libertad y seguridad de las personas, Colex, Madrid, 1994.

FORTUNY BERENGUER, Montserrat, El delito de secuestro del artículo 164 del Código Penal y sus diferencias con el delito de detención ilegal y con el delito de coacciones según la jurisprudencia del Tribunal Supremo

http://www.elderecho.com/tribuna/penal/delito-secuestro-diferencias-detencion-ilegal-

coacciones_11_838180001.html

GARCÍA MORILLO, Joaquín, El derecho a la libertad personal (Detención privación y restricción de libertad), Universidad de Valencia, Valencia, 1995.

GONZÁLEZ FERRER, Campo Elías, Secuestro Extorsivo, Revista Lex No. 8, 1977.

LA VERDAD PANAMA, Condenado por fingir su propio secuestro, 8 de junio de 2018.

https://www.laverdadpanama.com/condenado-por-fingir-su-propio-secuestro/

MINISTERIO DE SEGURIDAD PÚBLICA SISTEMA NACIONAL INTEGRADO DE ESTADÍSTICAS CRIMINALES SIEC, Informe de criminalidad, 2016

MORAS MOM, Jorge/ DAMIANOVICH, Laura T., Delitos contra la libertad, Ediar, Buenos Aires, 1972.

NACIONES UNIDAS, Manual de lucha contra el secuestro, Nueva York, 2006

SERRANO GOMEZ, Alfonso/ SERRANO MAILLO, Alfonso, SERRANO TARRAGA, María Dolores y VASQUeZ GOnZAleZ, Carlos, Curso de Derecho Penal, Parte Especial, 3a edición, Dykinson, Madrid, 2016.

VIVES ANTÓN, Tomás, La libertad como pretexto, Tirant lo Blanch alternativa, Madrid, 1995.

\section{Campo Elías Muñoz A.}

Maestría en Derecho con Especialización en Ciencias Penales. Universidad de Panamá; Facultad de Derecho y Ciencias Políticas (2005-2006) Graduado 2011. XX Curso de Postgrado en Derecho en la especialidad de Derecho Penal. Universidad de Salamanca, España, curso de 60 horas, 2007.Licenciatura en Derecho y Ciencias Políticas (1999-2003), Graduado Tercer Puesto de Honor 2005, Capitulo Sigma Lambda. Universidad de Panamá; Facultad de Derecho y Ciencias Políticas. Correo electrónico: campoema@gmail.com

Artículo recibido: 2 de julio de 2018

Aprobado: 26 de julio de 2018 
